\title{
Experimental carbon dioxide pulmonary embolization after vena cava laceration under pneumoperitoneum
}

\author{
Y. M. Dion, ${ }^{1,2}$ C. Lévesque, ${ }^{1}$ C. J. Doillon ${ }^{1,2}$ \\ ${ }^{1}$ Department of Surgery, Laval University, St-François d'Assise Hospital, 10 de l'Espinay, Quebec City, Quebec, Canada, G1L 3L5 \\ ${ }^{2}$ Quebec Biomaterials Institute, 10 de l'Espinay, Quebec City, Quebec, Canada, G1L 3L5
}

Received: 3 January 1995/Accepted: 12 May 1995

\begin{abstract}
The potential for pulmonary embolization following major venous laceration occurring during laparoscopic surgery has never been evaluated. Five anesthetized dogs were hemodynamically monitored with an arterial line and Swan-Ganz catheter. Observation by transesophageal echocardiography (TEE) allowed comparison with pulmonary artery pressure (PAP) recording. Under pneumoperitoneum, a $1-\mathrm{cm}$ venotomy was performed in the infrarenal vena cava and a total of 11 events were evaluated upon unclamping the venotomy. These results were compared with intravenous (i.v.) bolus injections of $15 \mathrm{cc}$ of $\mathrm{CO}_{2}$ (15 events) and of $100 \mathrm{cc}$ of $\mathrm{CO}_{2}$ (12 events). The animals were maintained euvolemic. In 2 out of the 11 (18\%) events which followed unclamping the venotomies, a few $\mathrm{CO}_{2}$ bubbles were seen in the right heart cavities. However, the quantity of gas was much less important than that seen after i.v. injection of $15 \mathrm{cc}$ and $100 \mathrm{cc}$ of $\mathrm{CO}_{2}$. There was no significant elevation of the PAP from pre-event values after venotomy or after i.v. injection of $15 \mathrm{cc}$ of $\mathrm{CO}_{2}$. However, there was a significant difference $(P<0.05)$ when these results were compared to the PAP values recorded after i.v. injection of $100 \mathrm{cc}$ of $\mathrm{CO}_{2}$. No dog died after these episodes of embolization. Massive i.v. injection of $\mathrm{CO}_{2}(>300$ cc) led to appearance of gas bubbles in the left heart cavities and death. This experiment suggests that caution should be exerted when laparoscopic surgery is performed beside large veins. Nevertheless, the observation that no gas embolism occurred in $82 \%$ of the cases after unclamping venotomies was unexpected. In contrast, many more gas bubbles were detected in the right heart after i.v. injection of only $15 \mathrm{cc}$ of $\mathrm{CO}_{2}$. TEE is a more sensitive indicator of pulmonary embolization than elevation of PAP.
\end{abstract}

Key words: Video laparoscopy — Pulmonary embo-

Correspondence to: $\mathrm{Y}$. M. Dion lism - Transesophageal echocardiography - Pulmonary artery pressure - Venotomy

Carbon dioxide $\left(\mathrm{CO}_{2}\right)$ embolization during laparoscopy is a recognized and potentially lethal complication $[3,13]$. Injury to the vena cava or a lumbar vein during dissection of retroperitoneal structures while performing laparoscopic aortic surgery [6] might lead to potentially disastrous complications.

In an experimental study performed under laparoscopy in dogs, we evaluated the potential for $\mathrm{CO}_{2}$ embolization from a $1-\mathrm{cm}$ vena cava laceration. The latter event was compared to the effect produced by $\mathrm{CO}_{2}$ bolus injections into the jugular vein.

\section{Materials and methods}

A pilot study was performed on two dogs. Data presented here come from a further study on five dogs. The animal experiments were approved by the institutional Animal Care Committee and surgery was conducted according to the guidelines of the Canadian Council for Animal Care. The dogs, weighing between 33 and $40 \mathrm{~kg}$ and lying supine on the operating table, were anesthetized with pentobarbital sodium $(25-35 \mathrm{mg} / \mathrm{kg})$. Anesthesia was maintained with a continuous intravenous infusion of pentobarbital $(5-10 \mathrm{mg} / \mathrm{kg} / \mathrm{h})$ [27]. Under endotracheal intubation, they were artificially ventilated with a volumetric Bird respirator with a tidal volume of $7-8 \mathrm{ml} / \mathrm{kg}$, a frequency of 10-12 breaths/min, and an oxygen content of the air mixture of $25 \%$. The ventilator was adjusted to maintain arterial $\mathrm{PO}_{2}$ between 95 and $135 \mathrm{mmHg}$ and arterial $\mathrm{PCO}_{2}<40 \mathrm{mmHg}$ [26]. An arterial line was inserted into the left carotid artery and connected to a pressure module M1006A (Hewlett-Packard Ltd. Montréal, Canada). A Swan-Ganz catheter connected to a similar module (HewlettPackard) was inserted into the pulmonary artery for measurement of pulmonary artery pressure (PAP). The left internal jugular vein was dissected to allow insertion of a catheter for blood-sample withdrawal and $\mathrm{CO}_{2}$ bolus injection.

A Duplex color ultrasound unit, a Hewlett-Packard Sonos 1000 cardiovascular imaging system, model $77030 \mathrm{~A}$, was equipped with a transesophageal electrode (TEE), an Omniplane TEE transducer 
$5.0-3.7 \mathrm{mHz}$, which was introduced into the esophagus between 30 and $40 \mathrm{~cm}$ of the incisives in order to display in real time the four chambers of the heart (Fig. 1). In all dogs, the Swan-Ganz catheter could be seen in the right ventricle. The instrument settings were adjusted for each dog to eliminate as much random noise as possible. Random noise was defined as soft gray particles that were not moving with blood flow. Gas bubbles were defined as echogenic particles that moved with flow.

Following a midline abdominal incision, the vena cava was exposed after incision of the retroperitoneum. Seven 10-mm trocars were inserted: one for the three-dimensional camera (Carl Zeiss Canada, Don Mills, Ontario, Canada), four for surgical instruments, and two for retractors. The midline incision was then closed. After systemic heparinization $(100 \mathrm{IU} / \mathrm{kg}$, followed by a continuous i.v. infusion of $40 \mathrm{IU} / \mathrm{kg}$ ), the inferior vena cava was clamped with laparoscopic Debakey forceps (R. Laborie Surgical Ltd., Brossard, Quebec, Canada) under laparoscopic control. A 1-cm longitudinal venotomy was made in the infrarenal vena cava with a laparoscopic knife (R. Laborie Surgical Ltd.) while maintaining a $12-15-\mathrm{mmHg}$ pneumoperitoneum using a Laparoflator (Karl Storz Gmbh, Tuttlingen, Germany). Unclamping was performed for $10 \mathrm{~s} \mathrm{(25-30} \mathrm{cc}$ of blood was lost during unclamping as measured by the quantity suctioned after each attempt). Blood loss was compensated by i.v. infusion of Ringer's lactate in order to maintain euvolemia.

In the five dogs, a total of 11 events (unclamping) were recorded and $\mathrm{CO}_{2}$ embolization was evaluated by PAP measurements and visual assessment of appearance of gas bubbles in the right heart as shown by the TEE. (Measurements made with the TEE were recorded in VHS format for later consultation.) Between each event, the vena cava was kept occluded with Debakey forceps.

Three of the five dogs were injected through the left internal jugular vein catheter with boluses of $15 \mathrm{cc}$ of $\mathrm{CO}_{2}$, for a total of 15 events, at a pressure of $15 \mathrm{mmHg}$, regulated by the Storz insufflator which served earlier to maintain the pneumoperitoneum. Gas was transferred from the insufflator into an appropriate-size syringe and injected into the vein using a three-way Stopcock tubing system Between each event, a sufficient lag period (3-10 min) was allowed for $\mathrm{CO}_{2}$ bubbles to disappear from the right ventricle. The three dogs were then injected for a total of 12 events with $100 \mathrm{cc}$ of $\mathrm{CO}_{2}$ at $15 \mathrm{mmHg}$ pressure. At the end of the experiment, a massive i.v. bolus of more than $300 \mathrm{cc}$ of $\mathrm{CO}_{2}$ administered as previously described led to death of all dogs.

Statistics used were the Friedman's test and the NewmannKeuls multiple comparisons test.

\section{Results}

With TEE, the four cardiac chambers can be easily observed (Fig. 1). In two events following venotomy, a few $\mathrm{CO}_{2}$ bubbles (Fig. 2) were observed in both right atrium and ventricle of the same dog. Movement of individual bubbles from the right atrium to the right ventricle was easily seen on videotape. The other 9 $(82 \%)$ events did not lead to visualization of $\mathrm{CO}_{2}$ bubbles.

As little as $15 \mathrm{cc}$ of $\mathrm{CO}_{2}$ injected as a bolus in the left internal jugular vein led to a rapid filling of both right heart cavities (Fig. 3). At echocardiography, multiple gas bubbles were seen in both right heart cavities. A mass of fused gas bubbles could be observed in the right ventricle. It was replaced with individual bubbles within seconds.

Injection of $100 \mathrm{cc}$ of $\mathrm{CO}_{2}$ (Fig. 4) was accompanied with the appearance of gas bubbles in both right heart cavities. A larger mass of fused gas bubbles was observed in the right ventricle compared to that seen after the 15-cc injection. On videotape, the right heart cavities cleared of gas bubbles within minutes. No bubbles were noted in the left heart cavities.
No dogs died during or after these repeated episodes of embolization.

The five dogs expired upon i.v. bolus injection of $300-500 \mathrm{cc}$ of $\mathrm{CO}_{2}$ (Fig. 5).

During those procedures, no significant difference in the mean PAP could be detected between the after venotomy events and events noted after injection of 15 cc of $\mathrm{CO}_{2}$ (Fig. 6). However, a significant difference $(P$ $<0.05$ ) was noted with baseline levels when $100 \mathrm{cc}$ of $\mathrm{CO}_{2}$ were injected. A significant difference $(P<0.05)$ was also noted between PAP of dogs submitted to a venotomy or injected with $15 \mathrm{cc}$ of $\mathrm{CO}_{2}$ and the PAP of dogs injected with $100 \mathrm{cc}$ of $\mathrm{CO}_{2}$.

\section{Discussion}

Since it is known that hypovolemia with decreased central venous pressure (expansion of the intravascular volume has been suggested as one element of treatment of air embolism [19]) invites embolic phenomena $[21,25]$, this experiment was designed to evaluate the effect of pneumoperitoneum on euvolemic animals with normal hemodynamic parameters prior to embolization.

Is accidental injury to the inferior vena cava likely to lead to massive pulmonary gas embolism and its dreaded complication, death? Our results demonstrate that, in our animal model, a $1-\mathrm{cm}$ injury to the inferior vena cava under a $\mathrm{CO}_{2}$ pneumoperitoneum of 12-15 $\mathrm{mmHg}$ does not lead to major hemodynamic effects, as shown by no significant elevation of the PAP.

A linear incision in the vena cava instead of excision of a predetermined amount of its wall was chosen in order to simulate a laceration which could occur during performance of a surgical procedure on organs close to the vein. No tissue covered the venotomy during unclamping. A 10-s waiting period before the venotomy was closed was selected, taking into account the amount of blood loss. That amount (25-30 cc) was reasonable and easy to compensate with Ringer's lactate. We also considered the fact that $10 \mathrm{~s}$ appear sufficiently long to the surgeon who looks at the hemorrhage without attempting to control it manually or, in the case of laparoscopy, with instruments already present in the surgical field. Moreover, major uncontrollable bleeding encountered during laparoscopy would dictate cessation of pneumoperitoneum and immediate laparotomy.

In 2 of $11(18 \%)$ events recorded following venotomies, gas bubbles were seen in the right heart cavities at echocardiography. However, this phenomenon is not comparable to the larger quantities seen after intravenous bolus injection of $15 \mathrm{cc}$ of $\mathrm{CO}_{2}$. However, the $15 \mathrm{cc} \mathrm{CO}_{2}$ bolus did not lead to a significant increase in PAP as did the injection of a $100-\mathrm{cc} \mathrm{CO}_{2}$ bolus. The amount of gas present in the right heart cavities after i.v. injection of only $15 \mathrm{cc}$ is nevertheless impressive at echocardiography as shown in Fig. 3.

This raises the question, why did the pulmonary artery pressure not increase? Consequences of venous gas embolism depend on the rate, the amount, and the 


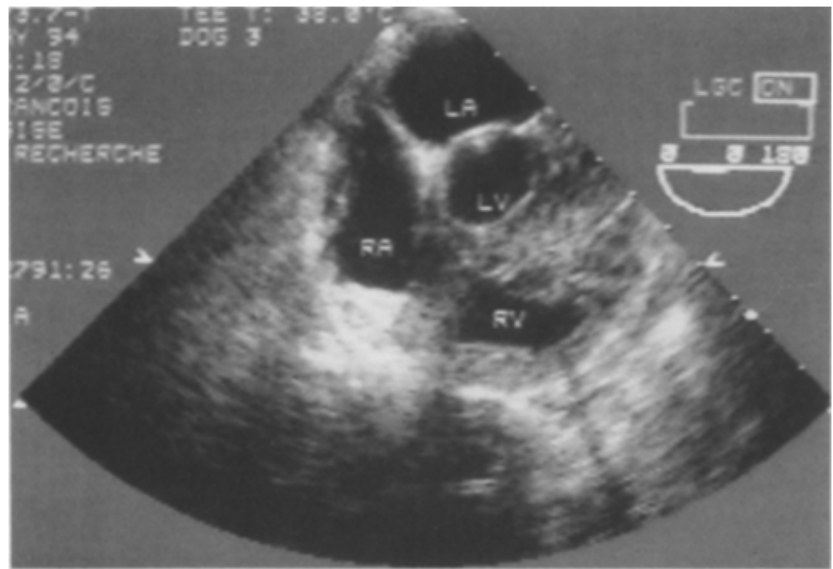

Fig 1. Normal dog transesophageal echocardiography showing the cardiac chambers. Right atrium $(R A)$; right ventricle $(R V)$; left atrium $(L A)$; left ventricle $(L V)$.

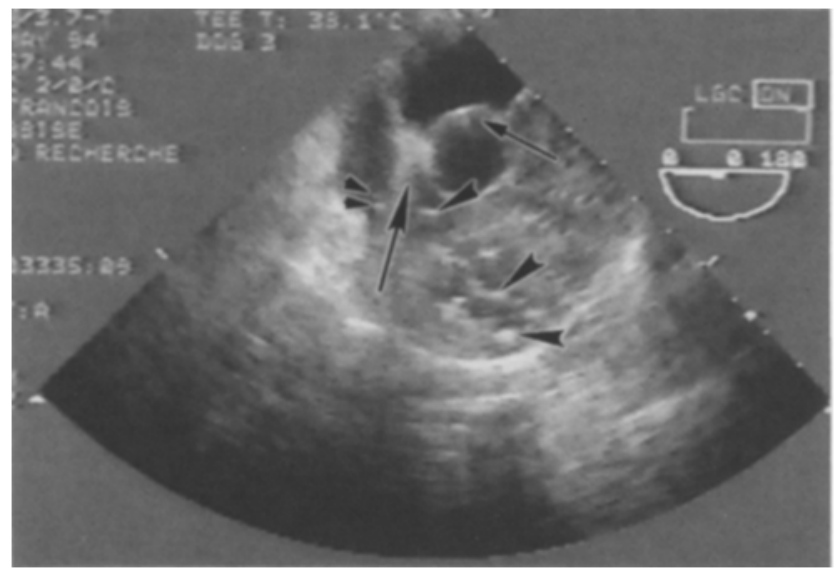

Fig. 2. A few $\mathrm{CO}_{2}$ bubbles are seen in the right atrium (small arrowheads) and ventricle (large arrowheads) after unclamping of a venotomy under pneumoperitoneum. This observation occurred only in $18 \%$ of the cases. Gas bubbles were defined as echogenic particles that moved with blood flow. They are more readily seen on videotape. Mitral (small arrow) and tricuspid (large arrow) valves are visualized.

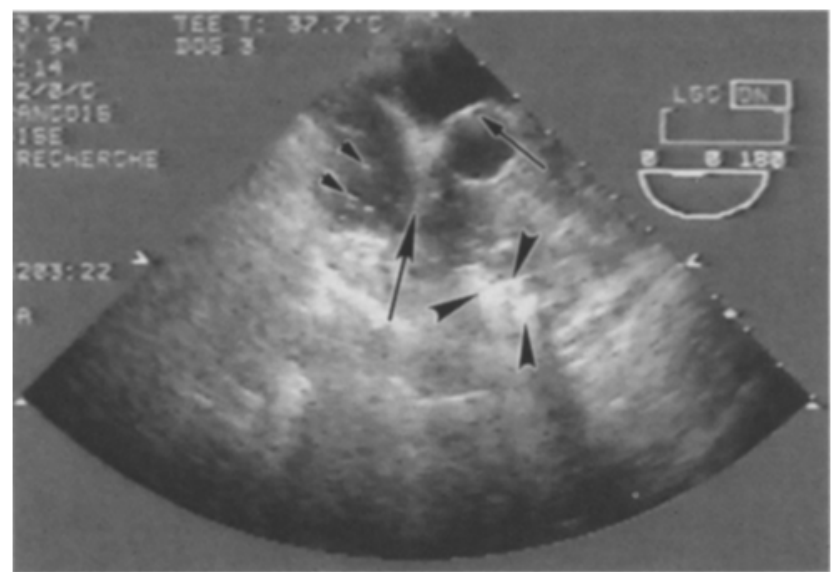

Fig. 3. Observation after i.v. injection of $15 \mathrm{cc}$ of $\mathrm{CO}_{2}$. The right atrium is filled with multiple air bubbles (small arrowheads). In the right ventricle, a mass of fused gas bubbles (large arrowheads) can be seen. On videotape, this mass of bubbles disintegrates and is replaced with individual bubbles which disappear within seconds. Mitral (small arrow) and tricuspid (large arrow) valves are seen.

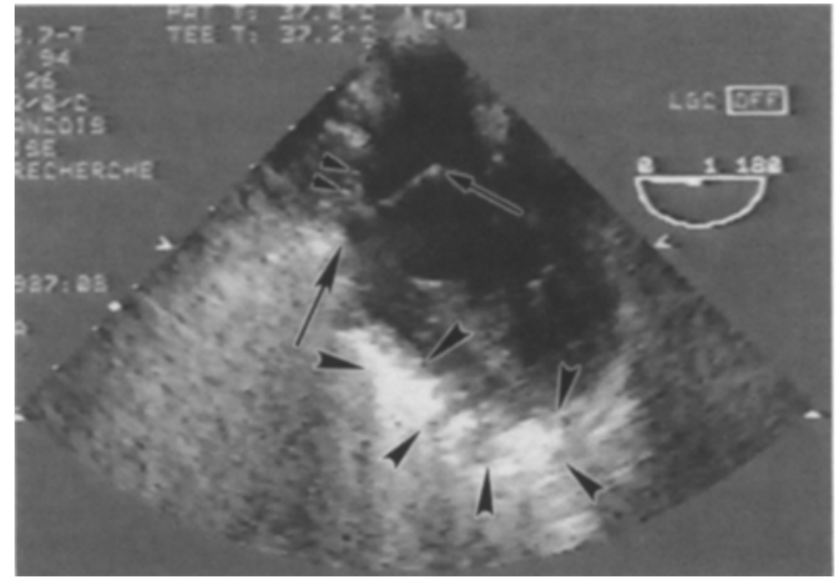

Fig. 4. Observation after i.v. injection of $100 \mathrm{cc}$ of $\mathrm{CO}_{2}$. The right atrium is filled with multiple gas bubbles (small arrowheads). The right ventricle is more than half filled with a single large mass of fused gas bubbles (large arrowheads). The videotape shows that this mass of gas bubbles disappears within a few minutes. The mitral (small arrow) and the tricuspid (large arrow) valves are shown. No echogenic particles that moved with flow are seen in the left heart cavities.

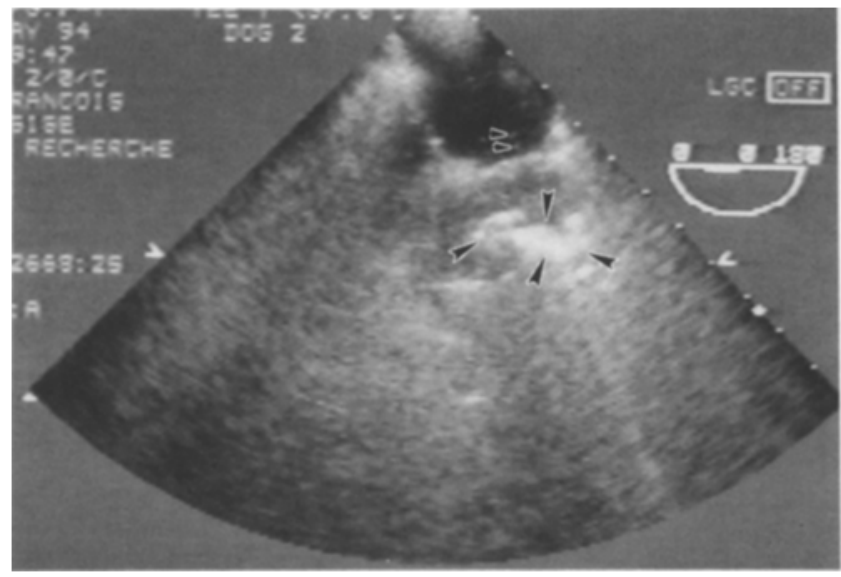

Fig. 5. Carbon dioxide bubbles (small arrowheads) are seen in the left atrium and a large mass of fused gas bubbles is present in the left ventricle (large arrowheads) after massive $(>300 \mathrm{cc}$ ) lethal i.v. in jection of $\mathrm{CO}_{2}$. Right heart cavities are obscured by embolic material.

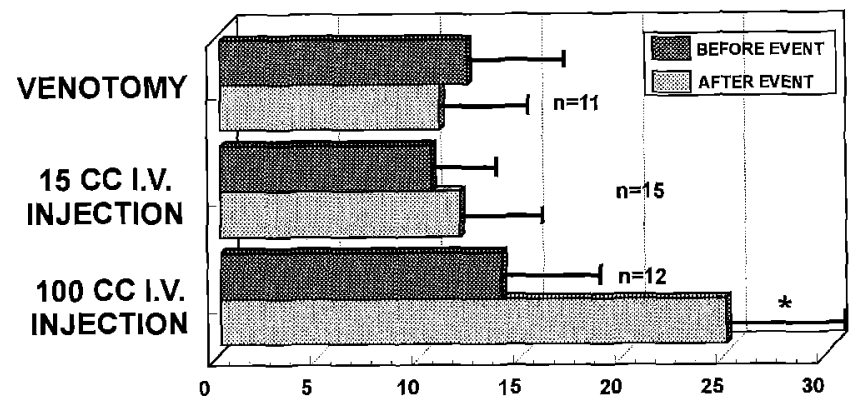

Fig. 6. Unclamping the venotomy or injection of $15 \mathrm{cc}$ of $\mathrm{CO}_{2}$ had no effect on mean pulmonary artery pressure (PAP). However, i.v. injection of $100 \mathrm{cc}$ of $\mathrm{CO}_{2}$ led to a significant elevation of PAP. 
nature of the gas introduced $[17,18]$. The magnitude of physiological distrubances caused by $\mathrm{CO}_{2}$ is 6.5 times less than that of air because of its higher blood solubility [23]. It has been shown in dogs that carbon dioxide shows exceptional behavior in that it has almost no effect on PAP with boluses ranging from 20 to $60 \mathrm{ml}$ injected in $1 \mathrm{~s}$ [24]. Reports of $\mathrm{CO}_{2}$ embolism have often commented on the rapid reversal of signs and the relatively benign postoperative course $[16,28]$. However, under continuous intravascular insufflation of $\mathrm{CO}_{2}$, other gases, chiefly oxygen, begin to diffuse into the bubbles [22]. The embolism then will require more time to be absorbed and a vicious cycle could be established. This may account for the reports of permanent injury and deaths following $\mathrm{CO}_{2}$ embolism [10, 20]. It has also been documented that as little as $100 \mathrm{ml}$ of air (the amount that flows through a 14-gauge needle in $1 \mathrm{~s}$ ) can be fatal in human beings [9]. From his experiments in dogs, Mehta et al. [14] concluded that there is a direct relationship between the volume of air embolism and the degree of cardiovascular responses and acid-base balance.

The hemodynamic effects of gas embolism using continuous intravenous air infusion or bolus injections of air are well documented. In dogs weighing between 18 and $22 \mathrm{~kg}$, an intravenous bolus injection of as little as $30 \mathrm{cc}$ of air will cause a rapid increase in PAP to $75-80 \mathrm{mmHg}$ [8]. A large intravenous bolus of air (3-8 $\mathrm{ml} / \mathrm{kg})$ will produce an "air lock" with complete mechanical obstruction of the right atrium and ventricle. The type of gas is not important for the maximum value of the resistance of the pulmonary vessels, unless the solubility of the gas is so high that some of the bubbles have already disappeared before the sites of obstruction are reached, as may hold for $\mathrm{CO}_{2}$ [24] . A slow infusion of air $(0.3 \mathrm{ml} / \mathrm{kg} / \mathrm{min})$ is absorbed across the pulmonary capillary-alveolar membranes without producing any clinical effect. At higher infusion rates, the gas bubbles lodging in the peripheral pulmonary arterioles provoke neutrophil clumping, activation of the coagulation cascade, and platelet aggregation. The release of chemical mediators produces pulmonary vasoconstriction, bronchospasm, pulmonary edema, and occasionally delayed pulmonary hemorrhage. Gas bubbles attached to fibrin deposits and platelet aggregates also mechanically obstruct the pulmonary vasculature, further increasing the pulmonary vascular resistance. The increase in right heart afterload leads to acute right heart failure with arrhythmias, electrocardiographic changes of myocardial ischemia, hypotension, and elevated central venous pressure [3].

In contrast, very little is known about the effects of repeated bolus injections of air (or $\mathrm{CO}_{2}$ ). A similar situation could be encountered by the laparoscopic surgeon who has difficulty securing a large bleeding vein. In one study [11], upon air injection in the main pulmonary artery, the PAP rose by $140 \%$. The changes disappeared within $13 \mathrm{~min}$. Basal levels of these parameters were not influenced despite manifold repetitions. Repeated embolizations caused similar results with only small variations. As shown in our study, rapid absorption of $\mathrm{CO}_{2}$ leads to quick disappearance of the $\mathrm{CO}_{2}$ bubbles and to reversal of pulmonary hypertension.

Blood is generally recognized by echocardiographers as echo-free [12]. For instance, no echocardiographic response to saline administration is usually observed other than an occasional single microbubble [12]. TEE permits detection of microbubbles as they emerge into the right atrium and ventricle. The $\mathrm{CO}_{2}$ bubbles are seen as high-density spots in the blood [26]. Small numbers of air bubbles of a mean size of $20-50 \mu \mathrm{m}$ can be seen as single hyperdense spots [26]. Vik et al. [27] showed that using a 7.5-MHz TEE probe, albumin-coated gas bubbles of $5-\mu \mathrm{m}$ size could be detected in the pulmonary artery when injected as a bolus. Our experiment demonstrates that detection of gas embolism is more precise using the TEE probe than relying on elevation of PAP. A bolus of $15 \mathrm{cc}$ of $\mathrm{CO}_{2}$ was easily visualized without concomitant elevation of PAP.

We do not advocate routine use of TEE since in clinical practice very few episodes of gas embolism have been reported. In three studies, the incidence of gas embolism was respectively 1 in 63,845 patients, 15 in 113,253 patients, and 8 in 50,247 patients [5].

Larger amounts of gas can cause appearance of gas bubbles in the left heart and cause paradoxical embolism. The sieving effect of the pulmonary microcirculation theoretically should prevent the passage of particles $8 \mu \mathrm{m}$ or greater in diameter [15]. However, this size limitation may apply only to rigid structures such as microspheres or microbubbles. For instance, contrast material [7] or platelet aggregates [4] have been demonstrated to cross the pulmonary capillary bed after intravenous infusion. Paradoxic air embolism with its potential for stroke and death in the absence of an intracardiac defect has been described [1]. Echogenic "speckles" of air in each of the cardiac chambers could be seen in some cases of complicated central venous catheterization. In experimental animals, Butler and Hill [2] showed that air infused into veins can enter the arterial system via the pulmonary microcirculation. In our experiment, gas bubbles regularly appeared in the left heart after massive i.v. injection of $\mathrm{CO}_{2}(>300 \mathrm{cc})$ but not after injection of 15 or $100 \mathrm{cc}$ of $\mathrm{CO}_{2}$ or after venotomy.

In summary, in our animal model, a few $\mathrm{CO}_{2}$ gas bubbles were seen in the right heart cavities in 2 out of $11(18 \%)$ events after venotomies created in the infrarenal vena cava under a $15-\mathrm{mmHg}$ pneumoperitoneum. These findings should suggest caution during surgery performed besides large veins. However, the amount of gas seen in the right cardiac cavities was much less important than that seen after an i.v. bolus of $15 \mathrm{cc}$ of $\mathrm{CO}_{2}$. This experiment also showed that TEE is an excellent monitoring device for $\mathrm{CO}_{2}$ embolization, as a minute amount of gas can be visualized. Pulmonary artery pressure elevates only after a larger quantity of $\mathrm{CO}_{2}$ has penetrated the right heart. We also noticed by TEE investigation that gas bubbles can be 
visualized in the left heart when the embolus is massive $(>300 \mathrm{cc})$. In our model, this phenomenon was a sign of impending hemodynamic failure.

\section{References}

1. Black M, Calvin J, Chan KL, Walley VM (1991) Paradoxic air embolism in the absence of an intracardiac defect. Chest 99(3): 754-755

2. Butler BD, Hill BA (1979) The lung as a filter for microbubbles. J Appl Physiol 47: 537-543

3. Chui PT, Gin T, Oh TE (1993) Anaesthesia for laparoscopic general surgery. Anaesth Intensive Care 21: 163-171

4. Connell RS, Swank RL, Webb MC (1973) Secondary microembolism after transfusions: an electron microscopic study. Biorheology 10: 561

5. De Platter RMH, Jones ISC (1989) Non-fatal carbon dioxide embolism during laparoscopy. Anaesth Intensive Care 17(3): 359-361

6. Dion YM, Katkhouda N, Aucoin A (1993) Laparoscopyassisted aortobifemoral bypass. Surg Laparose Endosc 3(5): $425-429$

7. Forsberg F, Liu JB, Burns PN, Merton DA, Goldberg B (1994) Artifacts in ultrasonic contrast agent studies. J Ultrasound Med 13: $357-365$

8. Gilbert JW, Berglund E, Dahlgren S, Ovenfors CO, Barnes R (1968) Experimental pulmonary hypertension in the dog; a preparation involving repeated air embolism. J Thor Cardiovasc Surg 55(4): 565-571

9. Hennessey B, FitzGerald A, Graham D (1993) Venous air embolism-keeping your patient out of danger. Am J Nursing 93(11): 54-56

10. Ivankovich AD, Albrecht RF, Zahed B, Bonnet RF (1974) Cardiovascular collapse during gynecological laparoscopy. $111 \mathrm{Med}$ J 145: 58-61

11. Josephson S (1970) Pulmonary hemodynamics during experimental air embolism; evidence of vasoconstriction. Scand J Clin Lab Invest 26(Suppl 115): 7-37

12. Mahony C, Spain C, Spain M, Evans J, Ferguson J, Smith MD (1994) intravascular platelet aggregation and spontaneous contrast. J Ultrasound Med 13: 443-450
13. McQuaide JR (1972) Air embolism during peritoneoscopy. S Afr Med J 46: 422-423

14. Mehta M, Sokoll MD, Gergis SD (1984) Effects of venous air embolism on the cardiovascular system and acid base balance in the presence and absence of nitrous oxide. Acta Anaesthesiol Scand 28: 226-231

15. Meltzer RS, Tickner EG, Popp RL (1980) Why do the lungs clear ultrasonic contrast? Ultrasound Med Biol 6: 263

16. Morison DH, Riggs JRA (1974) Cardiovascular collapse in laparoscopy. Can Med Assoc J 111: 433-437

17. O'Quin RJ, Lakshminarayan S (1982) Venous air embolism. Arch Intern Med 142: 2173-2176

18. Orebaugh SL (1992) Venous air embolism: clinical and experimental considerations. Crit Care Med 20: 1169-1177

19. Pearl RG, Larson CP (1986) Hemodynamic effects of positive end-expiratory pressure during continuous venous air embolism in the dog. Anesthesiology 64: 724-729

20. Root B, Levy MN, Pollack S, Lubert M, Pathak K (1978) Gas embolism death after laparoscopy delayed by "trapping" in portal circulation. Anesth Analg 57: 232-237

21. Smelt WLH, De Lange JJ (1990) Delayed air embolism during vascular surgery. Mt Sinai J Med 57(2): 112-116

22. Stauffer HM, Durant TM, Oppenheimer MJ (1956) Gas embolism. Radiology 66: 686-692

23. Steffey EP, Johnson BH, Eger EI (1980) Nitrous oxide intensifies the pulmonary arterial pressure response to venous injection of carbon dioxide in the dogs. Anesthesiology 52: 52-55

24. Verstappen FTJ, Bernards JA, Kreuzer F (1977) Effects of pulmonary gas embolism on circulation and respiration in the dog-I. Effects on circulation. Pflugers Arch 368: 89-96

25. Veldhuys JW (1985) Embolie gazeuse pendant la coelioscopie. Cah Anesthesiol 33(7): 577-581

26. Vik A, Brubakk AO, Hennessy TR, Jenssen BM, Ekker M, Slordahl SA (1990) Venous air embolism in swine: transport of gas bubbles through the pulmonary circulation. J Applied Physiol 69(1): $237-244$

27. Vik A, Jenssen BM, Brubakk AO (1992) Paradoxical air embolism in pigs with a patent foramen ovale. Undersee Biomed Res 19(5): $361-374$

28. Yacoub OF, Cardona I, Coveler LA, Dodson MG (1982) Carbon dioxide embolism during laparoscopy. Anesthesiology 57: $533-$ 535 